BROOKHAVEN NATIONAL IABORATORY Associated Universities, Inc. Upton, Long Island New York
Available from the Office of Technical Services Department of Commerce Washington 25, D. C.
Accelerator Department Cosmotron Division
Internal Report
BNL6430

$\mathrm{MOB}-4$ MASTER January 4, 1962

\title{
TIME DEPENDENCE OF SPACE CHARGE BEAM LOSSES IN THE COSMOTRON
}

\section{Q. Barton and E. J. Sacharidis}

For the past two years, studies of the Cosmotron intensity have indicated a failure of the linear increase of intensity with increase of injection current. Shortly after the earliest observation of this effect, an experiment was done by Snyder and Turner to determine whether or not the saturation represented the failure of some component or some fundamental process like space charge. (1) Their method consisted in observing the current in an ion chamber formed by a pair of horizontal plates above and below the beam arranged to collect the ions formed in the residual gas. (2) Such a device forms a particularly convenient monitor for this problem because it coes not reauire a bunched beam. The result indicated that the injected particles were indeed getting into the machine without intensity dependence. This establishes the fact that neither the various injection components nor the usual picture of transverse space charge are responsible for saturation. The latter effect shovld show in the injected current since weakening or detuning of the betatron focusing forces should cause beam losses in a few revolutions whereas the measurements showed no saturation through the forty or more turns of injection. (At that time the Van de Graaff injector was operated so that the energy of injection was constant during the injection time interval).

Shortly after the saturation was discovered, phenomena associated with azimuthal space charge were observed. (3) Subsequently, an extensive program of study was undertaken ${ }^{(4)}$ to compare these observations with theory. (5) It was shown in the course of these observations that the azimuthal space charge mechanism can form self bound charge density clusters in the phase space associated with the azimuthal coordinate. The radial extent of these clusters can be estimated and is found to be comparable to the radial extent 


\section{DISCLAIMER}

This report was prepared as an account of work sponsored by an agency of the United States Government. Neither the United States Government nor any agency Thereof, nor any of their employees, makes any warranty, express or implied, or assumes any legal liability or responsibility for the accuracy, completeness, or usefulness of any information, apparatus, product, or process disclosed, or represents that its use would not infringe privately owned rights. Reference herein to any specific commercial product, process, or service by trade name, trademark, manufacturer, or otherwise does not necessarily constitute or imply its endorsement, recommendation, or favoring by the United States Government or any agency thereof. The views and opinions of authors expressed herein do not necessarily state or reflect those of the United States Government or any agency thereof. 


\section{DISCLAIMER}

Portions of this document may be illegible in electronic image products. Images are produced from the best available original document. 


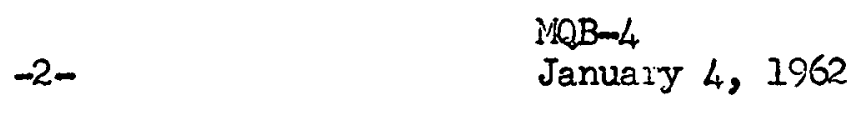

of the vacuum chamber. As the center of mass of the cluster moves through the phase space orbit, determined by the radio frecuency, the additional radial excursion might cause beam losses. One test of this nodel would be a measurement of the time dependence of the space charge losses. The model suggests losses on a time base comparable to the synchrotron oscillation period which is about $300 \mu \mathrm{sec}$ since the period for cluster formation is shorter.

In a recent experiment, (6) it was shown that the space charge saturation probably occurs less than $500 \mu \mathrm{sec}$ after the beginning of the injection process. This result along with the previous results of Snyder and Turner would seem to support the prediction of the model.

It is the purpose of this note to describe an experiment which permits the investigation of the intensity versus time through the entire time interval from the beginning of injection to the completion of rf capture. The method uses the induction electrode signal ${ }^{(7)}$ for the instantaneous measurement of beam intensity. Oscilloscope displays of this signal were photographed, the photographs projected onto plain white paper and hand traced. Base lines were filled in on the tracings and the area of the pulses measured with a polar planimeter. Figure 1 is a block diagram of the experimental set up used. A Tektronix 517 oscilloscope was used in conjunction with the "raster" and "synchronizer" to permit several successive observations of the induction signal during the same acceleration cycle. The raster is triggered by the injection peaker ${ }^{(8)}$ and produces a sawtooth voltage output which is applied directly to the vertical deflection electrodes of the 517 oscilloscope. It also produces a train of short pulses with perlod $\tau$. Both the sawtooth pulse and the short pulse train are delayed by time $\mathrm{T}$ from the initiating trigger. The synchronizer forms from the Cosmotron if system a train of trigger pulses gated by the raster output. Thus the output of the synchronizer is a train of pulses starting at time $T$ and having period $T$. with constant phase relationship with respect to the $\mathrm{rf}$ signal. These pulses are used to trigger the 517 oscilloscope whose horizontal scale was $0.5 \mu s e c$ per cm so that the entire width of the screen corresponded to a complete rotation period. Figure 2 is a typical example of the photographs thus obtained. 
The validity of this method recuires that the base line on the individual pictures can be established. During normal operation, the base line indeed cannot be determined during the capture process because particles are injected at all phases and it reouires some time to sweep out those particles outside the stable phase region. Therefore a modification of the injection system is suggested which injects only those particles near the phase stable region. The electrostatic "chopper" in the injection system (9) with the phase control and clippine amplifier (Fig. 1) are used for this purpose. The phase control provides a shifted in tine rf signal to the clipping amplifier wich in turn clips and amplifies that signal. The latter drives the chopper plates so that the beam is injected only during a half of the rf period with constant phase rerulated by the phase control. The Van de Graaff energy increases durine the injection period ${ }^{(10)}$ so that the injection scheme corresponds to filling of the region in phase space represented by the shaded portion of Fig. 3. It can be seen that even though the distribution includes many particles not inside the separatrix, these are lost to the inner or outer wall and a phase interval (between $A$ and $B$ on Fig. 3) containing no particles exists so that the base line is always unambiguously determined. This permits use of the induction electrode signal as an intensity measuring device through the entire time of interest from the beginning of injection until the completion of capture. It was noticed that the performance of the accelerator was unchanged by this change in the injection system.

The results are contained in three sets of photographs. In the first set $T$ was chosen ecual to 50 usec while in the second and third sets $T$ was $345 \mathrm{ksec}$. The spacing time $\tau$ vas about $60 \mu \mathrm{sec}$ for the first and second sets and about $250 \mathrm{usec}$ in the third set. Four measurements vere performed at each point in the first and second set and only two measurements in the third set. The intensities used were full, half, one-fifth, and one-tenth of the normal injection intensity. Those intensity levels were set using the attenuating screens (II) which reduce the intensity by randomly occluding particles without coinerently affecting any parameter of the machine. The increase of Van de Graff emittance caused by scattering from these screens inlght adversely affect the magnet acceptance efficiency but the intensity dependence of the losses from this effect should be opposite to that of space charge losses. 
The pulse to pulse variation of the machine during this experiment was rather lov by usual accelerator standards but was large enough to complicate this experiment considerably. The output of the induction electrode was also observed on a Tektronix 545 oscilloscope (Fig. I) with a slower time base and photographs taken of the same machine pulses used in the data. A typical picture is show in Fig. 4. The height of the envelope of each picture was measured at seven different times durin: the injection period and itted with a straight line. The slope of this line (M) is proportional to the injected current and since the injection period was constant throughout the experiment the slope is also proportional to the total charge injected. The average slope value multiplied by the screen attenuation factor as observed at the various intensities is show in Table $I$. To the extent that

\section{TABLE I.}

Attenuating Screen Transmission 1

$1 / 2$

$1 / 5$

$1 / 10$
Slope Multiplied by Attenuation Factor $9.97 \pm 0.48$ $10.59 \pm 0.25$ $11.23 \pm 0.56$ $10.38 \pm 0.38$

the number shown in this table is independent of intensity, the earlier results of Snyder and Turner are confirmed. The areas measured in the data pictures (I) were then normalized by dividing by this slope parameter. This procedure assumes the proportionality of output to input over the small intensity variations caused by machine jitter. The normalized results are then averaged for the four (or two) identical cases and presented in Table II. The assigned error is the standard deviation of the computed mean. This error was found to be considerably larger than estinates of the errors involved in the measurement process and hence must arise because of variations in machine parameters in ways not covered by the normalization.

The results for full and one-tenth intensities are plotted in Fig. 5. The half and one-fifth intensity points fall in between. It is seen that the relative losses of beam intensity increase with injection intensity (total injected charge) in agreement with the previous experiments and that most of 
NQB-4

-5- January 4, 1962

TABIE II.

I: Circulating charge at time $t$

M: Total charge injected during the injection period

$t:$ Time measured with the injection peaker signal as origin

\begin{tabular}{|c|c|c|c|c|c|}
\hline \multirow[b]{2}{*}{$\begin{array}{l}t \\
\left(\mu_{\mathrm{sec}}\right)\end{array}$} & \multicolumn{4}{|c|}{$I / M$} & \multirow[b]{2}{*}{ Remarks } \\
\hline & $\begin{array}{l}\text { at Full } \\
\text { Intensity }\end{array}$ & $1 / 2$ Intensity & 1/5 Intensity & $1 / 10$ Intensits & \\
\hline \multicolumn{6}{|c|}{ FIRST SET OF IEASUREMENTS } \\
\hline 50 & $0.132 \pm 0.006$ & $0.124 \pm 0.005$ & $0.099 \pm 0.006$ & $0.100 \pm 0.006$ & \multirow{2}{*}{$\begin{array}{l}\text { Four measurements } \\
\text { at each point. }\end{array}$} \\
\hline 95 & $0.383 \pm 0.008$ & $0.451 \pm 0.019$ & $0.386 \pm 0.013$ & $0.378 \pm 0.032$ & \\
\hline 155 & $0.745 \pm 0.010$ & $0.823 \pm 0.017$ & $0.747 \pm 0.019$ & $0.782 \pm 0.009$ & $n$ \\
\hline 215 & $0.878 \pm 0.011$ & $0.929 \pm 0.017$ & $0.935 \pm 0.020$ & $0.940 \pm 0.007$ & $n$ \\
\hline 270 & $0.834 \pm 0.018$ & $0.894 \pm 0.017$ & $0.902 \pm 0.017$ & $0.903 \pm 0.014$ & ln \\
\hline 325 & $0.655 \pm 0.016$ & $0.741 \pm 0.028$ & $0.739 \pm 0.015$ & $0.731 \pm 0.016$ & "n \\
\hline \multicolumn{6}{|c|}{ SECOND SET OF MEASUREMENTS } \\
\hline 345 & $0.587 \pm 0.027$ & $0.659 \pm 0.028$ & $0.667 \pm 0.030$ & $0.703+0.041$ & \multirow{7}{*}{ 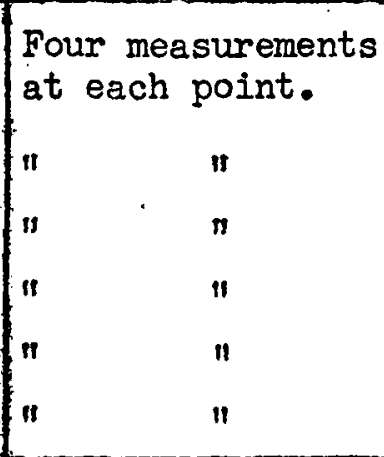 } \\
\hline 390 & $0.444 \pm 0.032$ & $0.496 \pm 0.025$ & $0.525 \pm 0.021$ & $0.563 \pm 0.040$ & \\
\hline 450 & $0.393 \pm 0.036$ & $0.444+0.023$ & $0.497 \pm 0.018$ & $0.510 \pm 0.041$ & \\
\hline 510 & $0.357 \pm 0.032$ & $0.416+0.026$ & $0.469 \pm 0.020$ & $0.503 \pm 0.044$ & \\
\hline 565 & $0.357 \pm 0.031$ & $0.406 \pm 0.030$ & $0.454 \pm 0.021$ & $0.485 \pm 0.035$ & \\
\hline 620 & $0.358 \pm 0.033$ & $0.435 \pm 0.030$ & $0.485 \pm 0.023$ & $0.530 \pm 0.033$ & \\
\hline 680 & $0.344 \pm 0.027$ & $0.426 \pm 0.027$ & - & -- & \\
\hline \multicolumn{6}{|c|}{ THIRD SET OF MEASUREMENTS } \\
\hline 350 & $0.611 \pm 0.069$ & $0.678 \pm 0.036$ & $0.622 \pm 0.006$ & $0.721 \pm 0.063$ & \multirow{2}{*}{$\begin{array}{l}\text { Two measurements } \\
\text { at each point. }\end{array}$} \\
\hline 630 & $0.391 \pm 0.111$ & $0.505 \pm 0.010$ & $0.461 \pm 0.001$ & $0.578 \pm 0.068$ & \\
\hline 900 & $0.331 \pm 0.098$ & $0.479 \pm 0.006$ & $0.440 \pm 0.001$ & $0.548+0.053$ & $"$ \\
\hline 1140 & $0.298 \pm 0.090$ & $0.434 \pm 0.004$ & $0.421 \pm 0.003$ & $0.528 \pm 0.053$ & $"$ \\
\hline 1380 & $0.283 \pm 0.087$ & $0.430 \pm 0.004$ & $0.406 \pm 0.005$ & $0.500+0.051$ & ii \\
\hline 1620 & 0.260110 .086 & $0.402 \pm 0.016$ & nansm & - & $n$ \\
\hline 1860 & $0.172 \pm 0.124$ & - & - & $-\infty$ & $\begin{array}{r}\text { One measurement } \\
\text { only }\end{array}$ \\
\hline
\end{tabular}

* The intensity here refers to the current of the injector. Thus full intensity corresponds to 1.74 ma instantaneous current going into the vacuum box during injection and hence to about $0.97 \times 10^{3 \mathrm{a}}$ injected parlicles totally. 


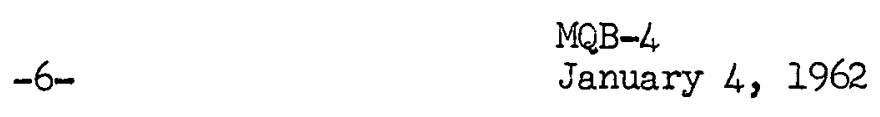

the losses take place in the time interval between the end of injection and the completion of the first synchrotron oscillation. The third set of measurements $(T=345 \mu \mathrm{sec}, T \approx 250 \mu \mathrm{sec})$ at half intensity, however, seem inconsistent in that the points lie above those corresponding to one-fifth intensity. This may be understood in terms of bad statistics (since only two measurements vere taken at each point in this set) or some mistake in recording the attenuation of the 517 oscilloscope.

This experimental technicue seems to provide a better means for studying this important problem than any other yet devised. We will continue this study with some changes suggested by the results of this run. These are:

1). More identical runs to redüçe uncertainty caused by pulse to pulse jitter。

2). Effort to understand source of this jitter.

3). Comparison of various injection schemes such as constant energy, Lee Teng scheme, injection of only a few turns, etc.

4). Possible improvements in electronic circuitry for increasing the number of observations available on a single machine pulse, etc.

5). Absolute calibration of transmission of attenuating screens and study of the change of emittance due to these screens.

6). Repetition of the ion chamber experiments.

7). Modification of the chopper circuitry to permit filling of different regions in phase space.

8). Comparison of the rate of beam loss with the rate of decay of azimuthal structure of the beam distribution.

This last point can be seen qualitatively by examining Fig. 2. The times shown on this picture span the period of greatest beam loss. The azimuthal structure has essentially disappeared by the fourth picture which corresponds to 410 usec by which time the intensity dependent losses are over. It would be desirable to examine this point in more detail.

The authors wish to acknowledge the assistance of all members of the Cosmotron Division who have assisted in this work. In particular, important contributions to the electronics were made by J. G. Cottingham, H. Einbinder, V. J. Kovarik, and E. J. Rogers. 


\section{References:}

(1). H. S. Snyder and C. M. Turner. Unpublished result.

(2). C. M. Turner, Cosmotron Internal Report CMT-10 (1958).

(3). M. Q. Barton \& H. S. Snyder. Unpublished result

(4). M. Q. Barton \& C. E. Nielsen. To be published in Proc. of 1961 Brookhaven International Conference on High Energy Accelerators.

(5). C. E. Nielsen, A. M. Sessler, \& K. R. Symon, Proc. Int. Conf. on High Energy Accelerators and Instrumentation - CERN, p. 239 (1959).

(6). M. Q. Barton. Unpublished result.

(7). C. E. Swartz, Rev. Sci. Instr. 24, 851 (1953).

(8). S. Giordano, G. K. Green, \& E. J, Rógers, Rev. Sci. Instr. 24, 848 (1953).

(9). J. G. Cottingham, W. H. Moore, E. J. Rogers, \& C. M. Turner, Rev. Sci. Instr. 24, 816 (1953).

(10). C. M. Turner, Cosmotron Internal Report CMT-13 (1961).

(11). C. M. Turner, Cosmotron Internal Report CMT-12 (1958).

\section{Figure Captions:}

Figure 1. Block diagram of the experimental apparatus.

Figure 2. A typical photograph of the 517 oscilloscope display.

Figure 3. A diagram showing the portion of phase space filled by our injection scheme.

Figure 4. A typical photograph of the 545 oscilloscope display.

Figure 5. Ratio of circulating charge to total injected charge versus time with injection intensity as parameter.

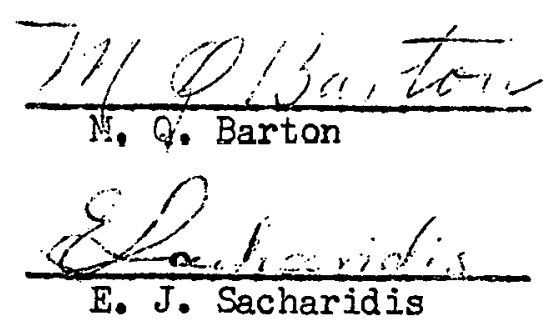




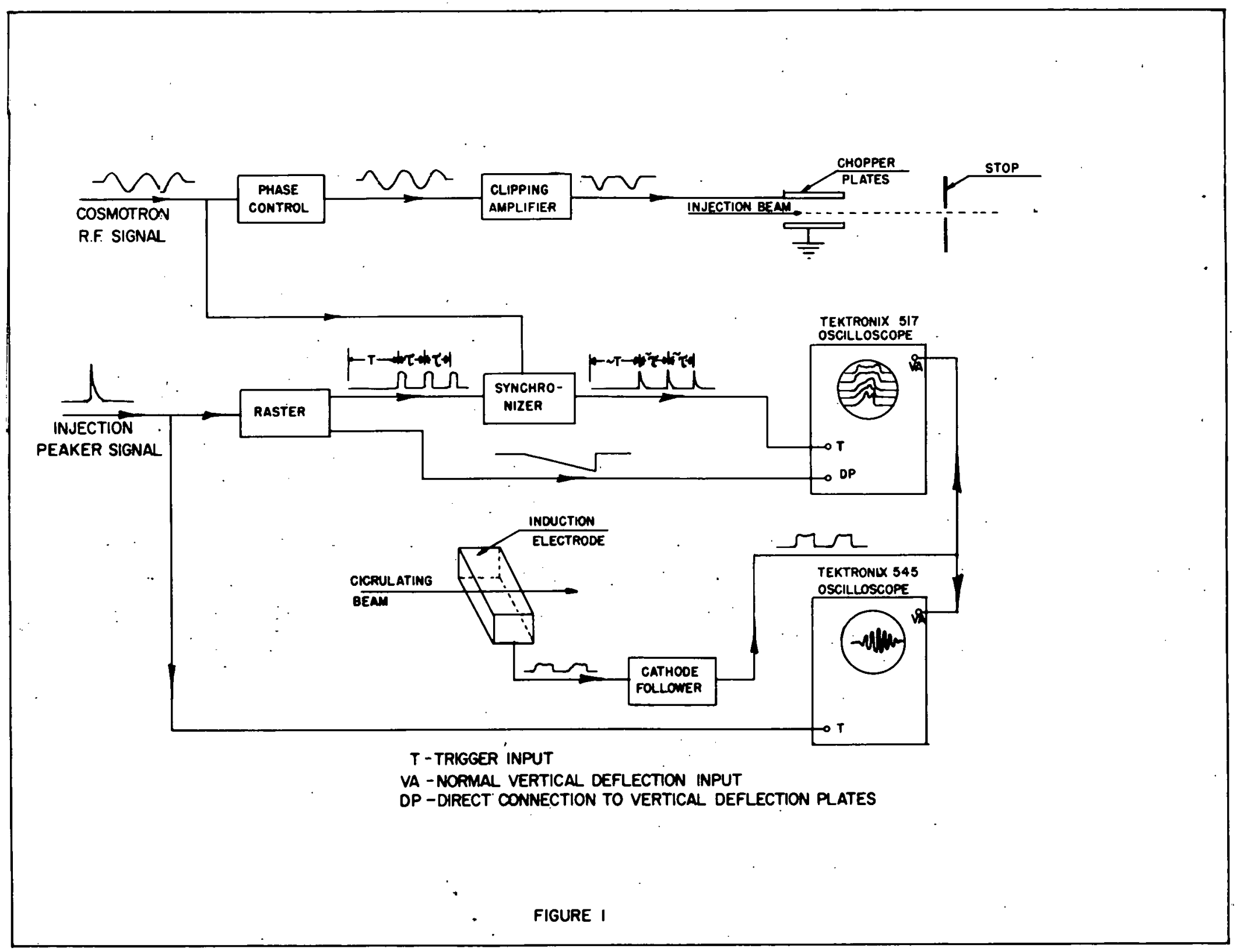


31

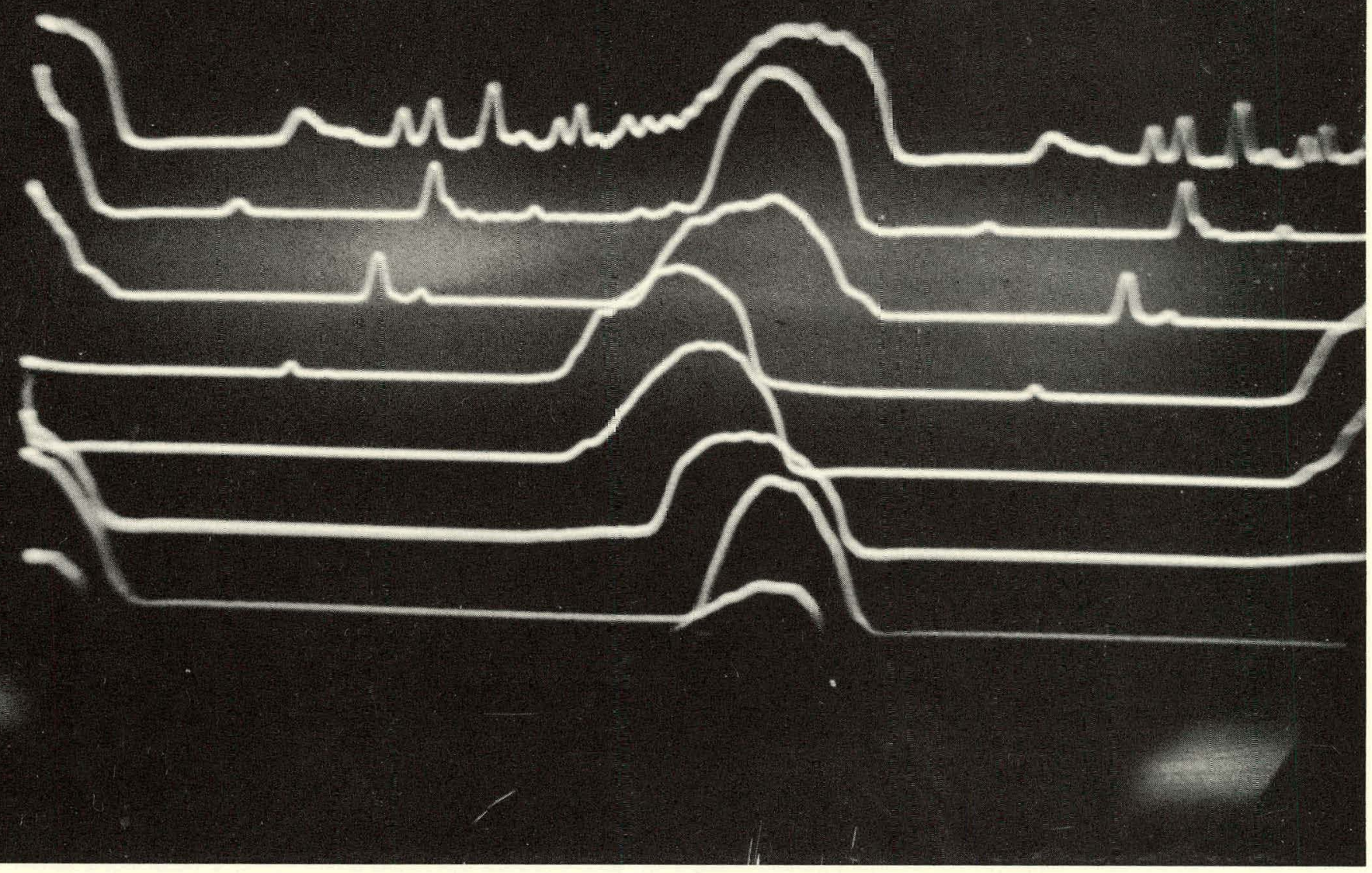

Fig. 2 


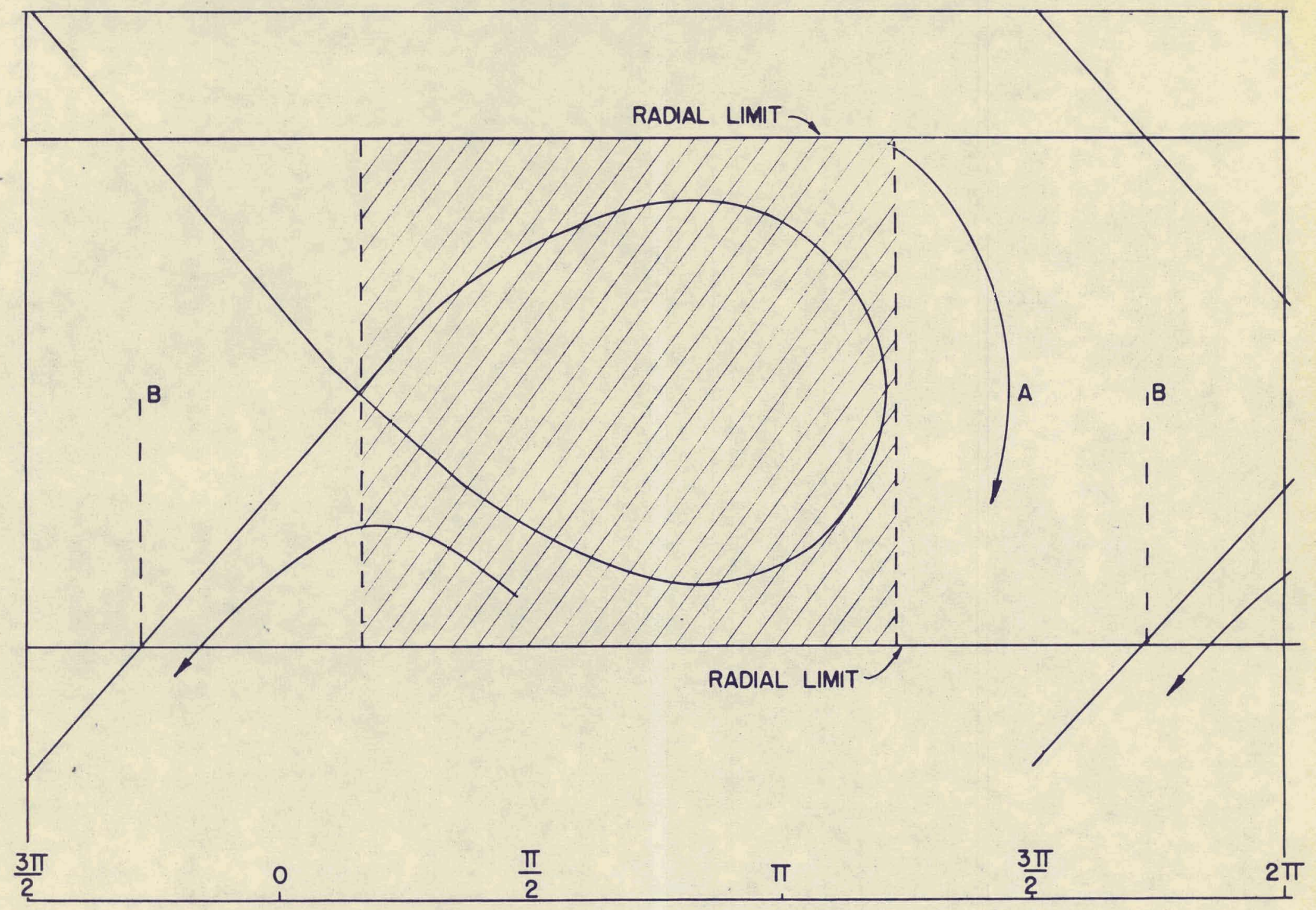

FIGURE 3 


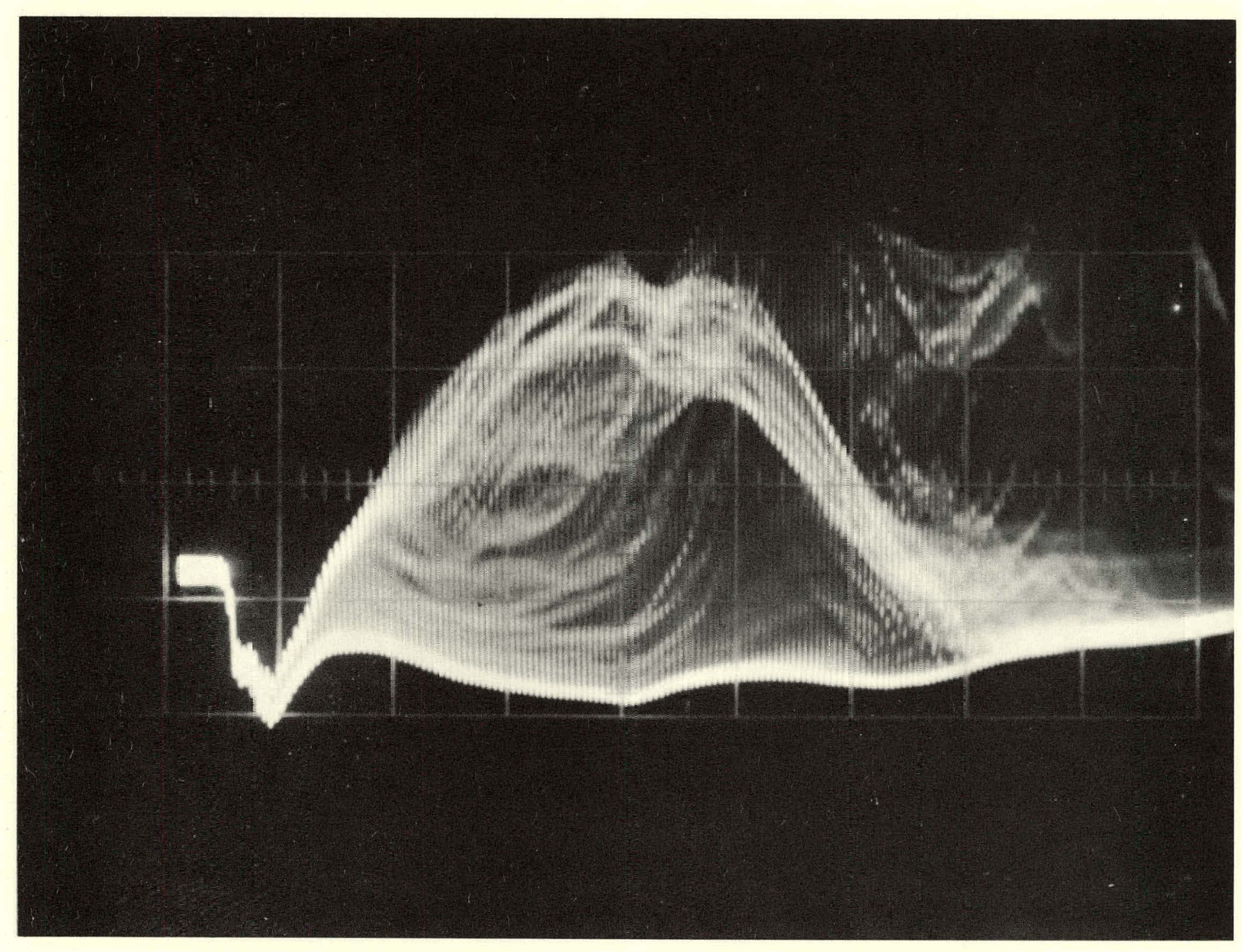

Fig. 4 


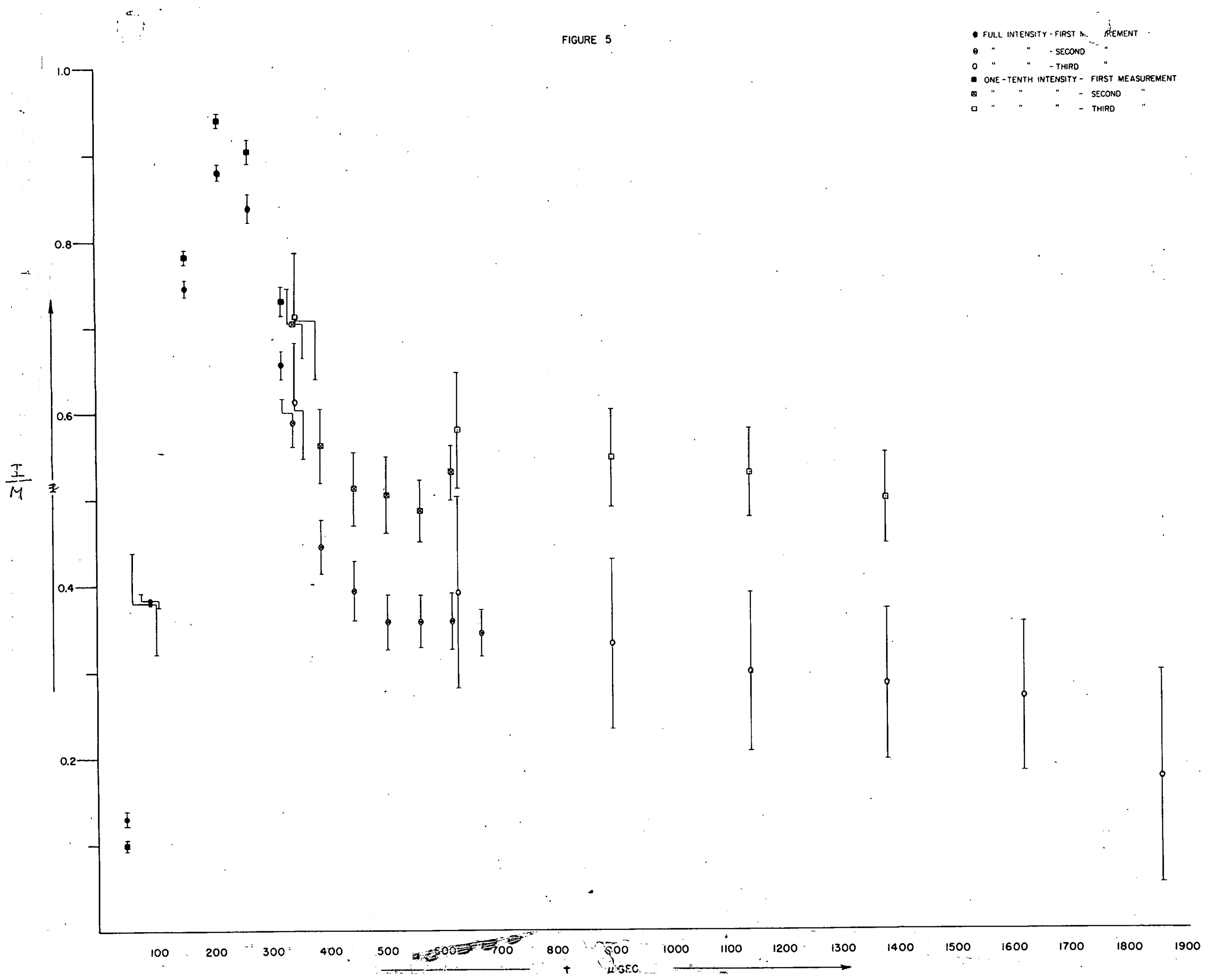

